\title{
RELAÇÃO DO SAQUE E RECEPÇÃO NA FINALIZAÇÃO DO ATAQUE NO VOLEIBOL ESCOLAR FEMININO INFANTIL E JUVENIL
}

\author{
Gilmário Ricarte Batista, Universidade Federal da Paraíba - UFPB, Paraíba-Brasil \\ Alysson Simões Bezerra, Universidade Federal da Paraíba-UFPB, Paraíba-Brasil \\ Yago Pessoa Costa, Universidade Federal da Paraíba - UFPB, Paraíba - Brasil \\ Idebaldo Grisi, Universidade Federal da Paraíba - UFPB, Paraíba - Brasil
}

\section{RESUMO}

O objetivo do presente estudo foi analisar a relação do saque e da recepção com o efeito da finalização do ataque no voleibol em equipes escolares nas categorias infantil e juvenil da Paraíba. Essa pesquisa foi descritiva observacional de forma transversal. A amostra foi composta por oito equipes de voleibol feminino das categorias infantil (12 a 14 anos) e juvenil (15 a 17 anos), participantes dos Jogos Escolares da Paraíba, Etapa Estadual de 2013. Foram observados seis jogos, três para de cada categoria, sendo analisados 687 saques, 584 recepções e 233 ataques.Em todas as análises foram encontradas um efeito significativo $(\mathrm{p}<0,001)$ na relação do saque e da recepção com o efeito da finalização do ataque para ambas às categorias. A qualidade do saque apresentou uma relação de dependência com a finalização do ataque tanto para o infantil quanto para o juvenil, respectivamente $\left(X^{2}=49,947, p<0,001 ; X^{2}=88,854, p<0,001\right)$. A qualidade da recepção também apresentou uma relação de dependência para o infantil e juvenil $\left(X^{2}=104,780, p<0,001 ; X^{2}=160,091, p<0,001\right)$. É possível que a qualidade da recepção e da criação de oportunidades do ataque da amostra em questão, não seja eficaz, em habilidade técnica para contribuir de forma positiva no efeito da finalização do ataque.

Palavras-Chave: Esporte escolar; Análise de jogo; Habilidade motora.

\section{RELATIONSHIP SERVE AND RECEPTION IN THE FINALIZATION OF THE ATTACK ON THE SCHOOL GAMES OF PARAÍBA}

\begin{abstract}
The objective of the study was to analyze the relationship of serve and reception with the effect the finalization of the attack on the school games of Paraíba. The sample was composed of eight women's volleyball teams of the "A" (12-14 years) and "B" (15-17 years), participants of the School Games of Paraíba State Stage 2013. Six matches were found: three of each category. Being analyzed 687 serves, 584 receptions and 233 attacks. In all analyzes, a significant effect $(\mathrm{p}<0.001)$ were found in respect of serve and reception with the effect of the finalization of attack for both the categories. The quality of serve showed a relationship of dependency with the completion of attack for Conexões: revista da Faculdade de Educação Física da UNICAMP, Campinas, v. 13, n. 1, p. 99-113, jan./mar. 2015. ISSN: 1983-9030
\end{abstract}


both "A" category and for category "B", ( $\left.\mathrm{X}^{2}=49,947, \mathrm{p}<0,001 ; \mathrm{X}^{2}=88,854, \mathrm{p}<0,001\right)$. The reception quality also showed a dependency relationship for all categories $(\mathrm{X} 2=$ 104.780, $\mathrm{p}<0.001, \mathrm{X} 2=160.091, \mathrm{p}<0.001)$. It is possible that the reception quality and creating opportunities Attack of the sample in question, it is not effective in technical skills to contribute positively in the effect the finalization of the attack.

Key-Words: School sport; Match analysis; Motor skill.

\section{RELACIÓN DEL SAQUE Y RECEPCIÓN EN LA FINALIZACIÓN DEL ATAQUE EN LOS JUEGOS ESCOLARES DE LA PARAÍBA}

\section{RESUMEN}

El objetivo del presente estudio fue analizar la relación del saque y de la recepción con el efecto de la finalización del ataque en los Juegos Escolares de la Paraíba. La amuestra fue compuesta por ocho equipos de voleibol femenino de las categorías "A" (12 a 14 años) y "B' (15 a 17 años), participantes de los Juegos Escolares de la Paraíba, Etapa Estadual de 2013. Se observaron seis juegos: tres de cada categoría. Siendo analizados 687 saques, 584 recepciones y 233 ataques. En todas las análisis fueron encontrados un efecto significativo $(\mathrm{p}<0,001)$ en la relación del saque y de la recepción con el efecto de la finalización del ataque para ambas las categorías, $\left(X^{2}=49,947, p<0,001 ; X^{2}=88,854\right.$, $\mathrm{p}<0,001$. La calidad del saque presentó una relación de dependencia con la finalización del ataque tanto para la categoría " $A$ " como para la categoría ' $B$ "', ( $X^{2}=104,780$, $\left.\mathrm{p}<0,001 ; \mathrm{X}^{2}=160,091, \mathrm{p}<0,001\right)$. Es posible que la calidad de la recepción y de la creación de oportunidades de ataque de la amuestra, no sea eficaz, en habilidad técnica para contribuir de forma positiva en el efecto de la finalización del ataque.

Palabras-Clave: Deporte escolar; Análisis del juego; Las habilidades motoras. 


\section{INTRODUÇÃO}

Na última década, a aplicação da análise de jogo para entender os diferentes aspectos de atuação do atleta ou de uma equipe desportiva tornou-se muito popular entre esporte e cientistas do esporte, ${ }^{1}$ além de ser um processo em constante evolução. ${ }^{2}$ Esse processo envolve a observação dos acontecimentos, notação dos dados e interpretação. ${ }^{3}$ Além disso, a análise pode ser realizada através de indicadores, sendo gerais do jogo, biomecânicos, técnicos e táticos, ${ }^{4}$ sendo primordial para ser utilizada no treinamento e na competição. ${ }^{5}$

Para Hughes e Franks $^{6}$ a identificação e interpretação dos padrões de eficácia do desempenho esportivo, constituem o principal aspecto na análise de jogo, envolvendo tanto atletas adultos ${ }^{7}$ quanto juvenis ${ }^{8}$ contribuindo para seus processos decisórios, bem como o planejamento e o controle dos treinamentos. ${ }^{5}$ Esta análise pode ser efetuada em diferentes perspectivas, tais como modelos de atividades dos atletas e das equipes, traços de atividades para resultados positivos, desenvolvimento de métodos de treinamento e tendências evolutivas das diferentes modalidades. ${ }^{2}$

Em modalidades esportivas como o voleibol, que vem sofrendo processos de evolução técnica e tática permanente, o que o torna um esporte coletivo altamente competitivo, ${ }^{9}$ percebe-se que a análise de jogo tem função fulcral para o desempenho esportivo. Nessa modalidade grande parte das investigações via análise de jogo abordam as seleções nacionais, ${ }^{10-13}$ servindo de parâmetros de desempenho para outros atletas. ${ }^{4}$

Entretanto, tais parâmetros podem ser extramente elevados quando relacionados com o voleibol escolar que possivelmente não é submetido a treinamentos sistematizados de forma intensiva. Portanto, percebe-se uma incipiência de informações na literatura acerca da análise de jogo em voleibol escolar, categoria essa considerada base para o esporte de alto rendimento.

Diante disso, a análise de jogo no esporte escolar pode contribuir para a formação de futuros atletas de alto rendimento, sobretudo pelo fato do Brasil ser sede dos próximos Jogos Olímpicos de 2016, o que faz que sejam necessárias investigações sistemáticas 
sobre a evolução esportiva. Dentre essas investigações no voleibol destaca-se a análise do complexo 1 (recepção, levantamento e ataque) ${ }^{14}$ que é caracterizada pela performance ofensiva das equipes (side-out). Diante disso, o presente estudo analisou a relação do saque e da recepção com o efeito da finalização do ataque em equipes de voleibol escolar feminino infantil e juvenil da Paraíba.

\section{MÉTODOS}

O presente estudo foi caracterizado como pesquisa descritiva observacional de forma transversal. A amostra do estudo foi composta por oito equipes de voleibol feminino, sendo quatro da categoria infantil (12 a 14 anos) e quatro da categoria juvenil (15 a 17 anos), participantes dos Jogos Escolares da Paraíba, Etapa Estadual de 2013. A Etapa Estadual reúne as equipes campeãs dos Jogos Escolares da Paraíba da Fase Regional. Foram observados seis jogos das fases finais, sendo as duas semifinais e finais (respectivamente, infantil e juvenil), os jogos de disputas de terceiro e quarto lugar não foram analisados. Foram analisados 687 saques, 584 recepções e 233 ataques.

Foram contatadas todas as oitos equipes de voleibol feminino da Etapa Estadual. Para identificar as equipes elegíveis, foi enviado um documento a Secretaria de Esporte, Juventude e Lazer (SEJEL) do Estado da Paraíba solicitando a relação das equipes finalistas bem como a autorização para filmagens dos jogos, documento que serviu de base para nortear a coleta de dados. Em seguida foi enviado um convite para as equipes solicitando a participação das mesmas, bem como a relação dos atletas atuantes nas equipes.

Os critérios de inclusão foram as equipes participantes da Etapa Regional e mediante assinatura do Termo de Consentimento Livre e Esclarecido (TCLE) e o termo de Assentimento. Os critérios de exclusão constituíram-se em jogos incompletos.

Foram avaliados os fundamentos do saque, da recepção, do levantamento e do ataque. O saque e a recepção foram analisados pela qualidade de execução e o efeito do ataque pelas ações ocasionadas pelo saque e recepção. O levantamento foi avaliado apenas para descrever os dados. As ações foram avaliadas através de uma escala de cinco itens ( 0 a 
4) conforme proposta de Eom e Schutz, ${ }^{15}$ sendo: item " 0 " (zero) - um erro que resulta na perda do ponto ou que não permite continuidade da jogada; item "1" (um) - uma execução pobre que não resulta diretamente na perda de um ponto ou side-out (virada de bola). Esta execução fornece uma situação negativa para a equipe do atleta e uma situação positiva para o adversário da equipe; item "2" (dois) - uma execução média, nenhuma equipe obtém vantagem diretamente no ataque ou contra-ataque; item "3" (três) - uma execução boa que não resulta diretamente na marcação do ponto, mas cria vantagem para a equipe que a executou; item "4" (quatro) - uma excelente execução. Ação que permite a melhor execução possível para a equipe nos casos da recepção e levantamento. Já nos casos do saque e do ataque é uma ação que permite marcação do ponto.

A qualidade do saque foi analisada pela execução pobre (item 1); pela execução média (item 2); pela execução boa (item 3); e pela execução excelente (item 4). Já a qualidade da recepção e o efeito do ataque foram avaliados incluindo todos os itens ( 0 a 4 ).

\section{Procedimentos de coleta de dados}

Todos os jogos foram filmados da parte superior do ginásio, possibilitando um ângulo em que toda a quadra de jogo pudesse ser observada. Em seguida os jogos foram analisados em vídeos e tabulados em planilha do Microsoft Excel e posteriormente transportados para programa estatístico para análise das variáveis do estudo. Antes de iniciar a coleta de dados, dois avaliadores, acadêmicos de educação física com experiência em voleibol, foram submetidos a programa de treinamento, durante dois meses, para padronização dos procedimentos da avaliação da escala utilizada no estudo.

Para análise dos dados foi utilizado a estatística descritiva, utilizando-se as frequências e percentagens. Para associação entre as variáveis investigadas, utilizou-se o teste do Qui-quadrado, com a correção de Monte Carlo, sempre que menos de $20 \%$ das células apresentaram valor inferior a 5. Foram utilizados os resíduos ajustados, no sentido de se identificar quais às células apresentaram significado estatístico na explicação da relação entre duas variáveis. Neste sentido, esta relação foi considerada apenas com valores 
superiores ao "2". Para todas as análises o nível de significância foi estabelecido em $5 \%$.

A análise de fiabilidade foi verificada após 30 dias, sendo avaliadas 67,4\% das ações, os valores de referências para este questionamento é de $10 \%{ }^{16}$ A fiabilidade intra observador e inter observador mostrou valores de Kappa entre 0,81 a 0,98 para todas as variáveis.

O estudo foi aprovado pelo Comitê de Ética em Pesquisa do Centro de Ciências da Saúde da Universidade Federal da Paraíba (CAEE 24380713.0.0000.5188). Todos os participantes assinaram o TCLE, após serem informados sobre o protocolo da pesquisa.

\section{RESULTADOS}

\section{Resultados da categoria infantil (12 a 14 anos)}

A qualidade do saque apresentou uma relação de dependência significativa com o efeito do ataque $\left(\mathrm{X}^{2}=49,947 ; \mathrm{p}<0,001\right)$ na categoria infantil (TABELA 1), revelando que o ponto de ataque ocorreu mais do que o esperado após o saque de execução pobre. $\mathrm{O}$ ataque que não resulta diretamente na marcação do ponto, mas que cria vantagens para que isso aconteça, ocorreu menos do que o esperado após o saque de execução média ($2,3)$ e mais do que o esperado após a execução do saque pobre $(4,6)$. Já o ataque que não resulta diretamente na perda do ponto, mas que cria situação negativa ocorreu mais do que o esperado após o saque de execução pobre $(2,5)$. Observou-se também que o erro do ataque ocorreu mais do que o esperado após qualquer forma de execução do saque, com exceção após o saque pobre $(-6,8)$ em que o esperado foi menor do que o ocorrido. $\mathrm{Na}$ análise dos dados foi verificado que foram utilizados dois tipos de saques, sendo por baixo e tipo tênis executado sem salto e sem deslocamento. 
Tabela 1 - Relação entre a qualidade do saque realizado e o efeito do ataque no voleibol feminino infantil dos Jogos Escolares da Paraíba da Etapa Estadual 2013

\begin{tabular}{cccccccc}
\hline Qualidade & & \multicolumn{5}{c}{ Efeito do ataque } \\
\cline { 3 - 7 } do Saque & Ocorrido & 50 & 9 & 4 & 19 & 13 & 95 \\
& Esperado & 72,1 & 4,8 & 2,4 & 8,9 & 6,8 & 95,0 \\
Execução & \% Saque & $52,6 \%$ & $9,5 \%$ & $4,2 \%$ & $20,0 \%$ & $13,7 \%$ & $100 \%$ \\
Pobre & \%Eficácia do ataque & $27,9 \%$ & $75,0 \%$ & $66,7 \%$ & $86,4 \%$ & $76,5 \%$ & $40,3 \%$ \\
& Resíduos ajustados & $-6,8$ & 2,5 & 1,3 & 4,6 & 3,2 & \\
& Ocorrido & 74 & 3 & 1 & 3 & 3 & 84 \\
Execução & Esperado & 63,7 & 4,3 & 2,1 & 7,8 & 6,1 & 84,0 \\
Média & \% Saque & $88,1 \%$ & $3,6 \%$ & $1,2 \%$ & $3,6 \%$ & $3,6 \%$ & $100 \%$ \\
& \%Eficácia do ataque & $41,3 \%$ & $25,0 \%$ & $16,7 \%$ & $13,6 \%$ & $17,6 \%$ & $35,6 \%$ \\
& Resíduos ajustados & 3,3 & $-0,8$ & $-1,0$ & $-2,3$ & $-1,6$ & \\
Execução & Ocorrido & 41 & - & 1 & - & 1 & 43 \\
Boa & Esperado & 32,6 & 2,2 & 1,1 & 4,0 & 3,1 & 43,0 \\
& \% Saque & $95,3 \%$ & - & $2,3 \%$ & - & $2,3 \%$ & $100 \%$ \\
& \%Eficácia do ataque & $22,9 \%$ & - & $16,7 \%$ & - & $5,9 \%$ & $18,2 \%$ \\
& Resíduos ajustados & 3,3 & $-1,7$ & $-0,1$ & $-2,3$ & $-1,4$ & \\
Execução & Ocorrido & 14 & - & - & - & - & 14 \\
excelente & Esperado & 10,6 & 0,7 & 0,4 & 1,3 & 1,0 & 14,0 \\
& \%Eficácia do ataque & $7,8 \%$ & - & - & - & - & $100 \%$ \\
& Resíduos ajustados & 2,2 & $-0,9$ & $-0,6$ & $-1,2$ & $-1,1$ & $5,9 \%$ \\
Total & Ocorrido & 179 & 12 & 6 & 22 & 17 & 236 \\
& Esperado & 179,0 & 12,0 & 6,0 & 22,0 & 17,0 & 236,0 \\
& \% Saque & $75,8 \%$ & $5,1 \%$ & $2,5 \%$ & $9,3 \%$ & $7,2 \%$ & $100 \%$ \\
& \%Eficácia do ataque & $100 \%$ & 100,0 & $100 \%$ & $100 \%$ & $100 \%$ & $100 \%$ \\
\hline
\end{tabular}

Legenda: $0=$ execução errada ou que não permite continuidade da jogada; $1=$ execução pobre; $2=$ execução média; 3 = execução boa; $4=$ execução excelente. Nível de significância $\mathrm{p}<0,05$.

A qualidade da recepção apresentou uma relação de dependência significativa com o efeito do ataque $\left(X^{2}=104,780 ; p<0,001\right)$ na categoria infantil (TABELA 2). O ponto de ataque ocorreu menos do que o esperado após a recepção de execução pobre $(-2,8)$ e mais do que o esperado após a execução média $(2,2)$ e excelente $(2,7)$. $\mathrm{O}$ ataque que não resulta diretamente na marcação do ponto, mas cria vantagens para que isso aconteça ocorreu mais do que o esperado após a execução da recepção boa $(2,7)$ e da recepção excelente $(4,5)$. $\mathrm{O}$ ataque em que nenhuma das equipes obtém vantagens ocorreu mais do que o esperado após a execução excelente $(2,6)$. O erro de ataque ocorreu mais do que o esperado após as recepções erradas $(4,4)$ e pobres $(6,2)$, enquanto que o erro de ataque ocorreu menos do que o esperado após a recepção de qualidade excelente $(-5,8)$, boa $(-4,2)$ e média $(-4,0)$. 
Tabela 2 - Relação entre a qualidade da recepção realizada e o efeito do ataque no voleibol feminino infantil dos Jogos Escolares da Paraíba da Etapa Estadual 2013

\begin{tabular}{|c|c|c|c|c|c|c|c|}
\hline \multirow{2}{*}{$\begin{array}{c}\text { Qualidade } \\
\text { da Recepção }\end{array}$} & & \multicolumn{6}{|c|}{ Efeito do ataque } \\
\hline & & $\mathbf{0}$ & 1 & 2 & 3 & 4 & Total \\
\hline \multirow{5}{*}{$\begin{array}{c}\text { Execução } \\
\text { errada ou } \\
\text { que não } \\
\text { permite } \\
\text { continuidad } \\
\text { e da jogada }\end{array}$} & Ocorrido & 45 & - & - & - & - & 45 \\
\hline & Esperado & 33,5 & 2,4 & 1,2 & 4,4 & 3,4 & 45,0 \\
\hline & \% Recepção & $100 \%$ & - & - & - & - & $100 \%$ \\
\hline & \%Eficácia do ataque & $27,1 \%$ & - & - & - & - & $20,2 \%$ \\
\hline & Resíduos ajustados & 4,4 & $-1,8$ & $-1,2$ & $-2,4$ & $-2,2$ & \\
\hline \multirow{5}{*}{$\begin{array}{c}\text { Execução } \\
\text { pobre }\end{array}$} & Ocorrido & 82 & 1 & - & - & 1 & 84 \\
\hline & Esperado & 62,5 & 4,5 & 2,3 & 8,3 & 6,4 & 84,0 \\
\hline & \% Recepção & $97,6 \%$ & $1,2 \%$ & - & - & $1,2 \%$ & $100 \%$ \\
\hline & $\%$ Eficácia do ataque & $49,4 \%$ & $8,3 \%$ & - & - & $5,9 \%$ & 37,7 \\
\hline & Resíduos ajustados & 6,2 & $-2,2$ & $-1,9$ & $-3,8$ & $-2,8$ & \\
\hline \multirow{5}{*}{$\begin{array}{l}\text { Execução } \\
\text { média }\end{array}$} & Ocorrido & 23 & 6 & 2 & 7 & 7 & 45 \\
\hline & Esperado & 33,5 & 2,4 & 1,2 & 4,4 & 3,4 & 45,0 \\
\hline & \% Recepção & $51,1 \%$ & $13,3 \%$ & $4,4 \%$ & $15,6 \%$ & $15,6 \%$ & $100 \%$ \\
\hline & \%Eficácia do ataque & $13,9 \%$ & $50 \%$ & $33,3 \%$ & $31,8 \%$ & $41,2 \%$ & $20,2 \%$ \\
\hline & Resíduos ajustados & $-4,0$ & 2,6 & 0,8 & 1,4 & 2,2 & \\
\hline \multirow{5}{*}{$\begin{array}{c}\text { Execução } \\
\text { boa }\end{array}$} & Ocorrido & 6 & 3 & 1 & 5 & 3 & 18 \\
\hline & Esperado & 13,4 & 1,0 & 0,5 & 1,8 & 1,4 & 18,0 \\
\hline & \% Recepção & $33,3 \%$ & $16,7 \%$ & $5,6 \%$ & $27,8 \%$ & $16,7 \%$ & $100 \%$ \\
\hline & \%Eficácia do ataque & $3,6 \%$ & $25,0 \%$ & $16,7 \%$ & $22,7 \%$ & 17,6 & $8,1^{*} \%$ \\
\hline & Resíduos ajustados & $-4,2$ & 2,2 & 0,8 & 2,7 & 1,5 & \\
\hline \multirow{5}{*}{$\begin{array}{l}\text { Execução } \\
\text { excelente }\end{array}$} & Ocorrido & 10 & 2 & 3 & 10 & 6 & 31 \\
\hline & Esperado & 23,1 & 1,7 & 0,8 & 3,1 & 2,4 & 31,0 \\
\hline & \% Recepção & $32,3 \%$ & $6,5 \%$ & $9,7 \%$ & $32,3 \%$ & $19,4 \%$ & $100 \%$ \\
\hline & \%Eficácia do ataque & $6,0 \%$ & $16,7 \%$ & $50 \%$ & $45,5 \%$ & $35,3 \%$ & $13,9 \%$ \\
\hline & Resíduos ajustados & $-5,8$ & 0,3 & 2,6 & 4,5 & 2,7 & \\
\hline \multirow{4}{*}{ Total } & Ocorrido & 166 & 12 & 6 & 22 & 17 & 223 \\
\hline & Esperado & 166,0 & 12,0 & 6,0 & 22,0 & 17,0 & 223 \\
\hline & \% Recepção & $74,4 \%$ & $5,4 \%$ & $2,7 \%$ & $9,9 \%$ & $7,6 \%$ & 100 \\
\hline & \%Eficácia do ataque & $100 \%$ & $100 \%$ & $100 \%$ & $100 \%$ & $100 \%$ & $100 \%$ \\
\hline
\end{tabular}

Legenda: $0=$ execução errada ou que não permite continuidade da jogada; $1=$ execução pobre; $2=$ execução média; $3=$ execução boa; $4=$ execução excelente. Nível de significância $\mathrm{p}<0,05$.

\section{Resultados da categoria juvenil (15 a 17 anos)}

A qualidade do saque apresentou uma relação de dependência significativa com o efeito do ataque $\left(\mathrm{X}^{2}=88,854 ; \mathrm{p}<0,001\right)$ na categoria juvenil (TABELA 3). O ponto de ataque ocorreu mais do que o esperado após o saque de execução pobre $(5,1)$ e menos no saque de execução boa $(-4,0)$. $\mathrm{O}$ ataque que não resulta diretamente na marcação do ponto, mas cria vantagens para que isso aconteça ocorreu mais do que o esperado após o saque de execução pobre $(3,7)$. Em relação ao ataque em que nenhuma das equipes obtém vantagens ocorreu mais do que o esperado após o saque de execução média $(2,6)$ e menos após a execução boa $(-2,6)$. $\mathrm{O}$ ataque que não resulta diretamente na perda de um ponto, mas que cria uma situação negativa ocorreu menos do que o esperado após o

Conexões: revista da Faculdade de Educação Física da UNICAMP, Campinas, v. 13, n. 1, p. 99-113, jan./mar. 2015. ISSN: 1983-9030 
saque de execução boa $(-2,1)$. No que se refere ao erro do ataque, o erro ocorreu mais do que o esperado após um saque de execução boa $(7,3)$ e menos após o saque de execução pobre $(-6,8)$. Na análise dos dados foi verificado que foram utilizados dois tipos de saque, sendo o por baixo e o tipo tênis, executado sem salto nem deslocamento.

Tabela 3 - Relação entre a qualidade do saque realizado e o efeito do ataque no voleibol feminino juvenil dos Jogos Escolares da Paraíba da Etapa Estadual 2013

\begin{tabular}{|c|c|c|c|c|c|c|c|}
\hline \multirow{2}{*}{\multicolumn{2}{|c|}{$\begin{array}{l}\text { Qualidade do } \\
\text { Saque }\end{array}$}} & \multicolumn{6}{|c|}{ Efeito do ataque } \\
\hline & & $\mathbf{0}$ & 1 & 2 & 3 & 4 & Total \\
\hline \multirow{5}{*}{$\begin{array}{l}\text { Execução } \\
\text { pobre }\end{array}$} & Ocorrido & 54 & 13 & 12 & 21 & 33 & 133 \\
\hline & Esperado & 84,3 & 8,9 & 11,4 & 11,4 & 17,1 & 133,0 \\
\hline & $\%$ Saque & $40,6 \%$ & $9,8 \%$ & $9,0 \%$ & $15,8 \%$ & $24,8 \%$ & $100 \%$ \\
\hline & \%Eficácia do ataque & $22,8 \%$ & $52,0 \%$ & $37,5 \%$ & $65,6 \%$ & $68,8 \%$ & $35,6 \%$ \\
\hline & Resíduos ajustados & $-6,8$ & 1,8 & 0,2 & 3,7 & 5,1 & \\
\hline \multirow{5}{*}{$\begin{array}{l}\text { Execução } \\
\text { média }\end{array}$} & Ocorrido & 80 & 10 & 18 & 11 & 14 & 133 \\
\hline & Esperado & 84,3 & 8,9 & 11,4 & 11,4 & 17,1 & 133,0 \\
\hline & $\%$ Saque & $60,2 \%$ & $7,5 \%$ & $13,5 \%$ & $8,3 \%$ & $10,5 \%$ & $100 \%$ \\
\hline & \%Eficácia do ataque & $33,8 \%$ & $40,0 \%$ & $56,2 \%$ & $34,4 \%$ & $29,2 \%$ & $35,6 \%$ \\
\hline & Resíduos ajustados & $-1,0$ & 0,5 & 2,6 & $-0,1$ & $-1,0$ & \\
\hline \multirow{5}{*}{$\begin{array}{l}\text { Execução } \\
\text { boa }\end{array}$} & Ocorrido & 90 & 2 & 2 & - & 1 & 95 \\
\hline & Esperado & 60,2 & 6,4 & 8,1 & 8,1 & 12,2 & 95,0 \\
\hline & $\%$ Saque & $94,7 \%$ & $2,1 \%$ & $2,1 \%$ & - & $1,1 \%$ & $100 \%$ \\
\hline & \%Eficácia do ataque & $38,0 \%$ & $8,0 \%$ & $6,2 \%$ & - & $2,1 \%$ & $25,4 \%$ \\
\hline & Resíduos ajustados & 7,3 & $-2,1$ & $-2,6$ & $-3,5$ & $-4,0$ & \\
\hline \multirow[t]{4}{*}{ Total } & Ocorrido & 237 & 25 & 32 & 32 & 48 & 374 \\
\hline & Esperado & 327,0 & 25,0 & 32,0 & 32,0 & 48,0 & 374,0 \\
\hline & $\%$ Saque & $63,4 \%$ & $6,7 \%$ & $8,6 \%$ & $8,6 \%$ & $12,8 \%$ & $100 \%$ \\
\hline & \%Eficácia do ataque & $100 \%$ & $100 \%$ & $100 \%$ & $100 \%$ & $100 \%$ & $100 \%$ \\
\hline
\end{tabular}

Legenda: $0=$ execução errada ou que não permite continuidade da jogada; $1=$ execução pobre; $2=$ execução média; 3 = execução boa; $4=$ execução excelente. Nível de significância $p<0,05$.

A qualidade da recepção apresentou uma relação de dependência significativa com o efeito do ataque $\left(\mathrm{X}^{2}=160,091 ; \mathrm{p}<0,001\right)$ na categoria juvenil (TABELA 4$)$. O ponto de ataque ocorreu menos do que o esperado após uma recepção pobre $(-4,0)$ e mais após a recepção excelente $(6,6)$. O ataque que não resulta diretamente na marcação do ponto, mas cria vantagens positivas ocorreu menos do que o esperado após a recepção pobre (3,3 ) e mais após a recepção excelente $(4,1)$. $\mathrm{O}$ ataque em que não beneficia vantagens para nenhuma das equipes ocorreu menos do que o esperado após a recepção pobre ($3,7)$ e mais após a recepção média $(4,1)$ e boa $(2,9)$.

Em relação ao ataque que não resulta diretamente na perda de um ponto, mas que criação situação negativa ocorreu menos do que o esperado após a recepção pobre $(-2,2)$ Conexões: revista da Faculdade de Educação Física da UNICAMP, Campinas, v. 13, n. 1, p. 99-113, jan./mar. 2015. ISSN: 1983-9030 
e mais após a recepção média $(2,5)$ e excelente $(2,3)$. Em relação ao ataque errado, observou-se que ocorreu mais do que o esperado após a recepção errada ou erro de sideout $(4,9)$ e após a recepção pobre $(8,1)$, e ocorreu menos do que o esperado após a recepção média $(-3,9)$ e excelente $(-8,0)$.

Tabela 4 - Relação entre a qualidade da recepção realizada e o efeito do ataque no voleibol feminino juvenil dos Jogos Escolares da Paraíba da Etapa Estadual 2013

\begin{tabular}{|c|c|c|c|c|c|c|c|}
\hline \multirow{2}{*}{$\begin{array}{l}\text { Qualidade da } \\
\text { Recepção }\end{array}$} & & \multicolumn{6}{|c|}{ Efeito do ataque } \\
\hline & & $\mathbf{0}$ & 1 & 2 & 3 & 4 & Total \\
\hline \multirow{5}{*}{$\begin{array}{c}\text { Execução } \\
\text { errada ou que } \\
\text { não permite } \\
\text { continuidade } \\
\text { da jogada }\end{array}$} & Ocorrido & 36 & - & - & - & - & 36 \\
\hline & Esperado & 23,3 & 2,5 & 3,2 & 3,2 & 4,8 & 36 \\
\hline & \%Recepção & $100 \%$ & - & - & - & - & $100 \%$ \\
\hline & \%Eficácia do ataque & $16,1 \%$ & - & - & - & - & $10,0 \%$ \\
\hline & Resíduos ajustados & 4,9 & $-1,7$ & $-2,0$ & $-2,0$ & 2,5 & \\
\hline \multirow{5}{*}{$\begin{array}{c}\text { Execução } \\
\text { pobre }\end{array}$} & Ocorrido & 117 & 4 & 2 & 3 & 5 & 131 \\
\hline & Esperado & 81,3 & 9,1 & 11,6 & 11,6 & 17,4 & 131,0 \\
\hline & \% Recepção & $89,3 \%$ & $3,1 \%$ & $1,5 \%$ & $2,3 \%$ & $3,8 \%$ & $100 \%$ \\
\hline & \%Eficácia do ataque & $52,2 \%$ & $16,0 \%$ & $6,2 \%$ & $9,4 \%$ & $10,4 \%$ & $36,3 \%$ \\
\hline & Resíduos ajustados & 8,1 & $-2,2$ & $-3,7$ & $-3,3$ & $-4,0$ & \\
\hline \multirow{5}{*}{$\begin{array}{l}\text { Execução } \\
\text { média }\end{array}$} & Ocorrido & 38 & 11 & 17 & 10 & 10 & 86 \\
\hline & Esperado & 53,4 & 6,0 & 7,6 & 7,6 & 11,4 & 86,0 \\
\hline & \% Recepção & $44,2 \%$ & $12,8 \%$ & $19,8 \%$ & $11,6 \%$ & $11,6 \%$ & $100 \%$ \\
\hline & \%Eficácia do ataque & $17,0 \%$ & $44,0 \%$ & $53,1 \%$ & $31,2 \%$ & $20,8 \%$ & $23,8 \%$ \\
\hline & Resíduos ajustados & $-3,9$ & 2,5 & 4,1 & 1,0 & $-0,5$ & \\
\hline \multirow{5}{*}{$\begin{array}{c}\text { Execução } \\
\text { boa }\end{array}$} & Ocorrido & 15 & - & 7 & 3 & 5 & 30 \\
\hline & Esperado & 18,6 & 2,1 & 2,7 & 2,7 & 4,0 & 30,0 \\
\hline & \% Recepção & $50,0 \%$ & - & $23,3 \%$ & $10,0 \%$ & $16,7 \%$ & $100 \%$ \\
\hline & \%Eficácia do ataque & $6,7 \%$ & - & $21,9 \%$ & $9,4 \%$ & $10,4 \%$ & $8,3 \%$ \\
\hline & Resíduos ajustados & $-1,4$ & $-1,6$ & 2,9 & 0,2 & 0,6 & \\
\hline \multirow{5}{*}{$\begin{array}{l}\text { Execução } \\
\text { excelente }\end{array}$} & Ocorrido & 18 & 10 & 6 & 16 & 28 & 78 \\
\hline & Esperado & 48,4 & 5,4 & 6,9 & 6,9 & 10,4 & 78,0 \\
\hline & \% Recepção & $23,1 \%$ & $12,8 \%$ & $7,7 \%$ & $20,5 \%$ & $35,9 \%$ & $100 \%$ \\
\hline & \%Eficácia do ataque & $8,0 \%$ & $40,0 \%$ & $18,8 \%$ & $50,0 \%$ & $58,3 \%$ & $21,6 \%$ \\
\hline & Resíduos ajustados & $-8,0$ & 2,3 & $-0,4$ & 4,1 & 6,6 & \\
\hline \multirow{4}{*}{ Total } & Ocorrido & 224 & 25 & 32 & 32 & 48 & 361 \\
\hline & Esperado & 2240 & 25,0 & 32,0 & 32,0 & 48,0 & 361,0 \\
\hline & \% Recepção & $62,0 \%$ & $6,9 \%$ & $8,9 \%$ & $8,9 \%$ & $13,3 \%$ & $100 \%$ \\
\hline & \%Eficácia do ataque & $100 \%$ & $100 \%$ & $100 \%$ & $100 \%$ & $100 \%$ & $100 \%$ \\
\hline
\end{tabular}

Legenda: $0=$ execução errada ou que não permite continuidade da jogada; $1=$ execução pobre; $2=$ execução média; 3 = execução boa; $4=$ execução excelente. Nível de significância $\mathrm{p}<0,05$.

\section{DISCUSSÃO}

Em todas as análises foram encontradas um efeito significativo $(\mathrm{p}<0,001)$ na relação do saque e da recepção com o efeito da finalização do ataque no voleibol feminino infantil e juvenil nos Jogos Escolares da Paraíba da fase final de 2013.

Conexões: revista da Faculdade de Educação Física da UNICAMP, Campinas, v. 13, n. 1, p. 99-113, jan./mar. 2015. ISSN: 1983-9030 
$\mathrm{Na}$ análise do estudo observou-se que apenas dois tipos de saques foram utilizados (por baixo e tênis) tanto no infantil quanto no juvenil o que pode ser justificada pela faixa etária e, sobretudo em atletas escolares. Nesse sentido, esses tipos de saques nessas categorias tem como finalidade dificultar a construção do ataque, o que pode assim facilitar a atuação do sistema defensivo. ${ }^{17}$

Em um estudo realizado por Gouveia, ${ }^{18}$ através de 9100 ações de 16 jogos de uma equipe infanto-juvenil feminino, também foi observado predominância de saque do tipo tênis $(80,50 \%)$ nas ações registradas para esse fundamento.

Em relação ao fundamento saque com o efeito do ataque no infantil, a execução do saque pobre revelou o previsível em que o ponto de ataque ocorreu mais do que o esperado tendo frequência de $13,7 \%$, mas o que chamou a atenção foi a tendência linear em que o erro de ataque ocorreu mais do que o esperado após os saques de execução média, boa e excelente $(52,6 \% ; 88,1 \% ; 95,3 \% ; 100 \%$, respectivamente). Diante disso, percebe-se que quanto melhor a qualidade do saque maior será a chance da equipe adversária errar o ponto de ataque.

No mesmo direcionamento, a categoria juvenil também revelou que o ponto de ataque ocorreu mais do que o esperado após o saque de execução pobre e média, mas com percentuais reduzidos em relação ao efeito do ataque (24,8\% e $10,5 \%$ respectivamente). $\mathrm{Na}$ execução do saque pobre o efeito do erro de ataque foi menor do que esperado apesar de demonstrar percentuais elevados enquanto que no saque de execução boa apresentou percentual elevado para o efeito do ataque, ou seja, quase $95 \%$ de erros.

Desta forma, acredita-se que a influência do saque no efeito do ataque na categoria juvenil esteja relacionado a agressividade do saque, o que pode estar interligada com a redução das possibilidades do ataque da equipe adversária. ${ }^{8}$ Além disso, pode-se supor que a falta de treinamento sistematizado das habilidades técnicas também podem ter contribuído para a redução do desempenho. Portanto, isso demonstra a importância do saque nessas categorias para desestruturar a organização do jogo das equipes adversárias. Em um estudo realizado por Costa et al. ${ }^{8}$ ao analisarem 11 jogos do 
Campeonato Mundial Juvenil masculino de 2007, verificaram que o ponto de ataque foi mais do que o esperado após o saque em apoio (tênis) tendo frequência de 52,6\% e o erro de ponto de ataque foi menos do que o esperado tendo frequência de 7,9\%.

$\mathrm{Na}$ análise da recepção com o efeito do ataque no infantil, revelou-se que a maior frequência de pontos acontece quando a recepção é considerada excelente, apesar de apresentar um percentual baixo com o efeito do ataque, ou seja, mesmo que a equipe consiga organizar o ataque não garante um valor satisfatório para a eficácia do ataque. Em contrapartida o ponto de erro de ataque acontece com percentuais elevados em todas as formas de execução da recepção.

Em relação ao juvenil, $O$ fato do erro de ataque ser o mais frequente em todas as qualidades da recepção com exceção da execução excelente em que o ponto de ataque foi mais frequente, revela uma fragilidade desse fundamento. Em um estudo realizado por Maia e Mesquita ${ }^{11}$ ao analisarem seis jogos de seleções nacionais seniores feminina da fase classificatória para o Campeonato Europeu de 2005, constatou que 50,2\% das recepções permitiam todas as opções de ataque demonstrando uma elevada qualidade de execução desse procedimento do jogo, contribuindo para a organização do jogo, enquanto que $36 \%$ das recepções não permitiam a organização do ataque. Estes resultados demonstram uma inversão ao presente estudo, embora tenha sido aplicado em equipes adultas. Costa et al. ${ }^{8}$ encontrou em atletas masculinos juvenis que o ponto de ataque ocorreu mais do que o esperado após a recepção que permitiu todas as opções de ataque (execução excelente) com uma frequência de $50,7 \%$ de pontos.

Considera-se a importância de pesquisas como esta para subsidiar e orientar a prática do voleibol escolar. No entanto, algumas fragilidades metodológicas do presente estudo podem ser destacadas, como o número de jogos registrados. Bem como, os poucos estudos encontrados com atletas feminino infantil e juvenil escolar que dificultaram a discussão do presente estudo. 


\section{CONCLUSÕES}

É possível que a qualidade da recepção e da criação de oportunidades do ataque da amostra em questão, não seja eficaz, em habilidade técnica para contribuir de forma positiva no efeito da finalização do ataque. Observou-se também que, apesar do saque não ter sido utilizado de forma agressiva, o mesmo contribuiu para desarticular a organização ofensiva dos adversários, isso porque a qualidade da recepção se apresentava deficitária.

\section{REFERÊNCIAS}

${ }^{1}$ SHAFIZADEH, M.; TAYLOR, M.; PEÑAS, C. L.; Performance consistency of international soccer teams in Euro 2012: a time series analysis. Journal of Human Kinetics, Katowice, v. 38, 213-225, sept. 2013.

${ }^{2}$ GARGANTA, J. A análise da performance nos jogos desportivos: revisão acerca da análise do jogo. Revista Portuguesa de Ciências do Desporto, Porto, v. 1, n. 1, p. 5764, 2001.

${ }^{3}$ HUGHES, M. National analysis. In: REILLY, T. (Ed.). Science and soccer. London: E \& FN Spon, 1996. p. 343-362,

${ }^{4}$ HUGHES, M.; BARLETT, R. JSS: editorial of the special edition on performance analysis. International Journal of Performance Analysis of Sport, Cyncoed, v. 2, p. 104-106, 2002.

${ }^{5}$ MATIAS, C. J. A. S.; GRECO, P. J. Análise de jogo nos jogos esportivos coletivos: a exemplo do voleibol. Pensar a Prática, Goiânia, v. 12, n. 3, p. 1-16, 2009.

${ }^{6}$ HUGHES, M.; FRANKS, I. Notational analysis of sport: systems for better coaching and performance in sport. 2nd ed. London: Routledge, 2004. 
${ }^{7}$ MORAES, J. C. Determinantes da dinâmica funcional do jogo de voleibol: estudo aplicado em seleções adultas masculinas. 2009. 328f. Tese (Doutorado em Ciências do Desporto) - Faculdade de Desporto, Universidade do Porto, Porto, 2009.

${ }^{8}$ COSTA, G. C. T. et al. Relação saque, recepção e ataque no voleibol juvenil masculino. Motriz, Rio Claro, v. 17, n. 1, p. 11-18, jan./mar. 2011.

${ }^{9}$ ANFILO, M. A. A prática pedagógica do treinador da seleção brasileira masculina de voleibol: processo de evolução tática e técnica na categoria infanto-juvenil. 2003. 182f. Dissertação (Mestrado em Educação Física) - Universidade Federal de Santa Catarina, 2003.

${ }^{8}$ COSTA, G. C. T. et al. Determinants of attack tactics in youth male elite volleyball. International Journal of Performance Analysis of Sport, Cyncoed, v. 11, n. 1, p. 96104, 2011.

${ }^{11}$ MAIA, N.; MESQUISTA, I. Estudo das zonas e eficácia da recepção em função do jogador recebedor no voleibol sênior feminino. Revista Brasileira de Educação Física e Esporte, São Paulo, v. 20, n. 4, p. 257-270, out./dez. 2006.

${ }^{12}$ MONTEIRO, R.; MESQUITA, I.; MARCELINO, R. Relationship between the set outcome and the dig and attack efficacy in elite male volleyball games. International Journal of Performance Analysis of Sport, Cyncoed, v. 9, n. 3, p. 294-305, 2009.

${ }^{13}$ AFONSO, J.; et al. Analysis of the setter's tactical action in high-performance women's volleyball. Kinesiology, Zagreb, v. 42, n. 1, p. 82-89, 2010.

${ }^{14}$ MONGE, A. M. Propuesta estructural del desarollo del juego em voleibol. In: MESQUITA, I.; MOUTINHO, C. A. S. S.; FARIA, R. (Ed.). Investigação em voleibol: estudos ibéricos. Porto: FCDEF-UP, 2003. p. 142-149. 
${ }^{15}$ EOM, H. J.; SCHUTZ, R. W. Statistical analyses of volleyball team performance. Research Quarterly for Exercise and Sport, Washington, v. 63, n.1, p. 11-18, mar. 1992.

${ }^{16}$ TABACHNICK, B.; FIDELL, L. Using multivariate statistics. Ney York: Harper \& Row, 1989.

${ }^{17}$ UREÑA, A.; et al. A. La facilatación defensiva a través del saque em el voleibol femenino de alto nível. Revista Motricidad, Granada, v. 6, p. 175-189, 2000.

${ }^{18}$ GOUVEA, F. L. Análise das ações de jogos de voleibol e suas implicações para o treinamento técnico-tático da categoria infanto-juvenil feminina (16 e 17 anos). 2005. 106f. Dissertação (Mestrado em Educação Física) - Faculdade de Educação Física, Universidade Estadual de Campinas, Campinas, 2005.

Recebido em: 30 jun. 2014

Aceito em: 19 fev. 2015

Contato: cajagr@gmail.com 